\title{
Distinguishing intergroup and long-distance relationships
}

\author{
Anne C. Pisor ${ }^{1,2, *}$ and Cody T. Ross ${ }^{2}$ \\ ${ }^{1}$ Department of Anthropology, Washington State University. United States. \\ ${ }^{2}$ Max Planck Institute for Evolutionary Anthropology. Dept. of Human Behavior, Ecology and Culture. Germany. \\ *Correspondence to anne_pisor@eva.mpg.de
}

Manuscript accepted at Human Nature

\begin{abstract}
Acknowledgments. Thanks to the Intercultural, Mosetén, and Tsimane' communities for their collaboration and friendship; to research assistants Bernabe Nate Añes, Jacinta Álvarez, and Amira Siquimen for their contributions to data collection, and to the Tsimane' Health and Life History Project for logistical support; to Michael Gurven, Dan Hruschka, Cristina Moya, and Ben Trumble for their contributions to study design; to Darcy Bird, Monique Borgerhoff Mulder, Dan Fessler, Paul Hooper, Adam Kenny, Kris Smith, Kim Sterelny, the Max Planck Institute for Evolutionary Anthropology Department of Human Behavior Ecology and Culture (MPI-EVA HBEC), WSU's 2021 Evolution of Human Sociality seminar, and two anonymous reviewers for helpful feedback and discussion. Thanks to MPI-EVA HBEC, the US National Science Foundation (DDRIG 1357209), the Wenner-Gren Foundation (Dissertation Fieldwork Grant 8913), the UCSB Broom Center, and UCSB Anthropology for funding.
\end{abstract}

\begin{abstract}
Intergroup and long-distance relationships are both central features of human social life, but because intergroup relationships are emphasized in the literature, long-distance relationships are often overlooked. Here, we make the case that intergroup and long-distance relationships should be studied as distinct, albeit related, features of human sociality. First, we review the functions of both kinds of relationship: while both can be conduits for difficult-to-access resources, intergroup relationships can reduce intergroup conflict while long-distance relationships are especially effective at buffering widespread resource shortfalls. Second, to illustrate the importance of distinguishing the two relationship types, we present a case study from rural Bolivia. Combining ethnography and two different experimental techniques, we find that the importance of intergroup relationships - and the salience of group membership itself - varies across populations and across methods. While ethnography revealed that participants often rely on long-distance relationships for resource access, we were unable to capture participant preferences for these relationships with a forced-choice technique. Taken together, our review and empirical data highlight that: (1) intergroup and long-distance relationships can have different functions and can be more or less important in different contexts, and (2) validating experimental field data with ethnography is crucial for work on human sociality. We close by highlighting future directions for research on long-distance relationships in humans.
\end{abstract}

Key words. intergroup relations, intergroup conflict, cooperation, sociality, parochial altruism

Environmental variability is a quintessential feature of the human niche, and social connections spanning distance have long helped humans respond to variability (Pisor \& Surbeck 2019; Pisor \& Jones 2021; Sterelny

5 2011). That said, the evolutionary literature has focused on the study of symbolically marked groups, meaning that the importance of long-distance relationships is often overlooked-especially as many long-distance relationships also cross group boundaries (Pisor \& Jones 2021;

10 Pisor \& Surbeck 2019). Here, we make the case that long-distance relationships and intergroup relationships should be studied as distinct, albeit related, features of human sociality.

We begin by reviewing the functions of intergroup

15 and long-distance relationships and discussing the possible history of selection that may have favored each. Groups can serve as containers for cooperation in humans (Boyd \& Richerson 1985), directing favoritism toward in-group individuals and competition toward out-

20 siders (Bowles \& Gintis 2004; Bowles \& Choi 2001). Intergroup relationships can reduce intergroup conflict
(Brewer 2010; Sherif 1966) and provide other benefits like facilitating trade (Jha 2013) and fostering resource specialization (Barth 1998). However, specialization is not always organized by group; when resource availability differs across space - due to specialization, for example, or because shortfalls in resource availability are spatially correlated-intergroup relationships may or may not provide access (Pisor \& Surbeck 2019; Pisor \& Jones 2021). Instead, long-distance relationships can be key.

Given intergroup relationships and long-distance relationships can serve different functions, we draw on field data to assess the relevance of group membership and location in the choice of new social partners. In a multiyear project in rural Bolivia, author ACP used a vari- 35 ety of quantitative and qualitative methods to study intergroup and long-distance relationships with three populations of horticulturalists. She designed an economic game to examine whether individuals weigh group membership when choosing a new social partner $(n=200)$; she found that the salience of group membership varied across populations, reflecting variation in the frequency 
and valence of intergroup interactions. However, ethnographic data suggested that long-distance relationships

45 were a central feature of rural Bolivian life. ACP came to speculate that distance might be more salient to partner choice in rural Bolivia than group membership per se.

To explicitly contrast preferences for forming inter50 group versus long-distance relationships, ACP conducted a second study in 2017 among two of the three horticultural populations $(n=125)$ using a specially designed forced-choice task. She found that even though many participants actively maintain long-distance rela-

55 tionships, they did not express preferences for these relationships in the forced-choice task. This study underscored that: (1) group membership and location are just two of many criteria used in determining the value of potential cooperative partners, and (2) due to response bi-

60 ases, demand characteristics, and a disconnect from realworld incentives and constraints, the preferences elicited by experimental methods may not correlate with realworld behavior. Taken together, the results from Bolivia indicate that intergroup relations, both positive and nega-

65 tive, can be overemphasized, and long-distance relationships overlooked, if researchers studying human sociality do not differentiate the two and do not cross-validate their results using multiple methods.

We conclude by discussing ideas for how researchers

70 can better study long-distance relationships, and review what we think should be the central foci of a research program characterizing role of long-distance relationships in human sociality.

\section{Distinguishing intergroup from long- distance relationships}

Intergroup relationships have long been a focus of social science research. In social psychology, intergroup relations is a commonly recognized subfield, while in evolutionary anthropology and evolutionary psychology,

80 research on human sociality often focuses on parochial altruism - in-group favoritism coupled with out-group competition (e.g., Pisor \& Ross 2021; Böhm et al. 2020). Because of the large literatures on intergroup relations and parochial altruism, researchers are often primed to

85 focus on groups when studying human sociality. Groups do structure human social networks, but as we detail here, long-distance relationships - which often cross group boundaries - are a central feature of these networks too (Jones et al. 2021).

Long-distance relationships are, of course, an implicit focus of fields studying trade, migration, intermarriage, and interactions with strangers-e.g., in archaeology (e.g., Minnis 1985), geography (e.g., Newman \& Dale 2007), and psychology (e.g., Berry 2001). Each are

95 important to human responses to environmental variability, and thus to human adaptation (Pisor \& Surbeck 2019; Pisor \& Jones 2021). That said, these different types of relationships (e.g., with trading partners, host families, and affinal kin) are usually not studied as part of a single category: relationships that typically span distance.

\subsection{What are intergroup relationships?}

Social scientists often use the word "group" without specifying what a group is (Pietraszewski 2021). In social psychology, two individuals are usually considered to be part of the same group if they have a shared fate or a shared identity (Böhm et al. 2020); these groups are considered "natural" groups if they are not created in the laboratory as part of an experiment (Balliet et al. 2014). When evolutionary anthropologists or evolutionary psychologists refer to groups, they too are gener- 110 ally referring to identity groups, especially when identity is observable to others (Smaldino 2019), when identity is symbolically marked (Moya \& Boyd 2015), or when identity is assigned to individuals by virtue of their relationships with third parties (Pietraszewski 2021). Alter- 115 natively, consistent with the literature on animal behavior, evolutionary scholars may refer to groups as aggregations of individuals that are in physical proximity with one another more often than they are with others (Kummer 1971).

When researchers study "natural" groups, they often focus on symbolically marked groups-e.g., ethnic groups, religious groups, or groups based on regional/national identity - in which individuals share norms of behavior and an origin story (e.g., Barth 1998; 125 Berry 2001). This is especially true in the parochial altruism literature, which usually focuses on favoritism toward members of the same ethnic group or (less frequently) members of the same religious group (Lang et al. 2019; Pisor \& Ross 2021). In keeping with common 130 usage, we will generally refer to intergroup relationships as ties between two individuals that cross ethnic or religious boundaries.

Intergroup relationships are thought to have two key adaptive functions: they (i) facilitate resource specializa- 135 tion and (ii) reduce costly intergroup conflict. For example, ethnic group identity is often structured around resource control or specialization (e.g., Yount et al. 2001; Cronk 2004) and intergroup relationships can enable gains to trade across these boundaries (Barth 1998; Jha 2013). Intergroup relationships permit not only the flow of physical resources between groups, but also the flow of ideas, norms, and technologies (Richerson et al. 2016). Additionally, intergroup relationships can reduce intergroup conflict (Pettigrew \& Tropp 2006). For example, intermarriage can be used to defuse tensions across group boundaries (Chapais 2009).

\subsection{What are long-distance relationships?}

Connections spanning distance are quite common across human societies, but their importance is often 150 overlooked in the study of human sociality (Wobst 1978). Individuals may form long-distance relationships when they engage in business, trade, or travel - and, today, such relationships can even be formed through the internet. When the potential benefits of long-distance re- 155 
lationships are large, cultural institutions can emerge that reduce the costs of forming and maintaining longdistance relationships (Jha 2013; Pisor \& Surbeck 2019). Such institutions may regulate the norms and expectations surrounding affinal relationships (Chapais 2009), ritual relationships (e.g., stock friendships, Bollig 2010), or patron-client relationships (Demps \& Winterhalder 2018).

There are two key benefits to long-distance relationships: risk management and non-local resource access (Pisor \& Surbeck 2019). Long-distance relationships allow individuals to manage the risk of resource shortfalls that can strike entire communities. Likewise, longdistance relationships can enable access to resources that 170 are never locally available (like tool-making materials, market goods, or even high-paying jobs) because they are clustered in space or because of specialization. Generally, as the distance between two individuals increases, shortfalls in their resource access become less correlated 5 and the diversity of resources the two can jointly access increases (Pisor \& Jones 2021). The distance required to achieve low correlation in shortfalls across a dyad will depend on the scale of the threats to resource security; for example, hurricanes can generate shortfalls im-

180 pacting large geographic areas, while pests often impact smaller areas. Similarly, the distance required to achieve diversity in joint resource access depends on the local ecology-for example, how far one must travel to reach a different ecozone (Pisor \& Jones 2021). The high re185 source diversity made possible by long-distance relationships is particularly important to humans because of our reliance on rare, often difficult-to-obtain nutrients, minerals, and raw materials (Pisor \& Surbeck 2019).

Two quintessential ethnographic case studies provide 190 examples of these key benefits - non-local resource access and risk management. San traditionally maintained hxaro relationships, with both kin and putative kin, living up to $200 \mathrm{~km}$ away (Wiessner 1982). An individual's hxaro partners often had access to resources that the indi-

195 vidual's band did not (like health clinics and schools) but also to the same resources (like game and water) which vary in their availability across time and space. When bands experienced correlated shortfalls - due, for example, to high winds or insect plagues - individuals would

200 often leave to visit their hxaro partners for extended periods of time (Wiessner 1977). In short, hxaro is a cultural institution that facilitates the formation and maintenance of long-distance relationships. Similarly, Massim traditionally practiced kula, a system of visitation and delayed exchange in which men would regularly visit their kula partners on different islands (Malinowski 1922). Like hxaro, kula both buffered local shortfalls and provided non-local resource access: communities on some islands specialized in pottery, which other communities desired;

210 when droughts struck, men from islands with limited arable land would visit partners on islands with larger food supplies (Irwin et al. 2019). Unlike hxaro, however, kula took place across linguistic boundaries (Malinowski
1922; Irwin et al. 2019), underscoring that long-distance relationships can cross group boundaries, but need not. 215

Importantly, the resources that move between longdistance social connections are not limited to consumable or utilitarian resources. Kula, for example, provided access to prestige goods from other places (Irwin et al. 2019; Malinowski 1922). Even in the ab- 220 sence of global communication systems or written language, cultural information, like that contained in stories, can travel across large distances (Ross \& Atkinson 2016); in turn, this transmitted information is often pertinent to resource production (Boyd \& Richer- 225 son 1985), coordination (Smith et al. 2017; McConvell 2015), and social organization (Yengoyan 1968). Longdistance ties can be solidified by marriage - generating affinal relationships - and can also expand the marriage market (Yengoyan 1968). Today, long-distance connec- 230 tions have become especially important for obtaining access to jobs (Pisor \& Jones 2021; Bird et al. 2019).

That said, long-distance relationships are not without their costs. In the absence of mass communication and transportation systems, maintenance of long-distance re- 235 lationships can require visitation (Minnis 1985) - costly, for example, due to lost production time and risk of attack during transit (Fitzhugh et al. 2011). Given costs like these, we should only expect individuals to form, maintain, and desire long-distance relationships when the ex- 240 pected benefits of these relationships outweigh the expected costs (Minnis 1985; Pisor \& Jones 2021).

\subsection{How do intergroup and long-distance relation- ships differ?}

Intergroup relationships and long-distance relation- 245 ships have partially overlapping functions, though they are by no means identical. Both intergroup relationships and long-distance relationships can offer access to resources that: (i) are not accessible to in-group members or social partners living close by, and/or (ii) are less cor- 250 related with an individuals' own resource holdings than those held by in-group members or partners living close by. However, long-distance relationships do not necessarily cross group boundaries. Because shared norms and institutions can minimize the costs of within-group in- 255 teractions (McElreath et al. 2003), the net benefits of long-distance relationships with in-group members will often be higher than the net benefits of long-distance relationships with out-group members (e.g., Ensminger 1994; Purzycki et al. 2016). Long-distance relationships 260 are also less likely to reduce parochial attitudes, which are best attenuated by frequent, positively valenced interactions (that is, interactions that go well) (Dovidio et al. 2003); such interactions are more likely when members of different groups live near one another (e.g., Bunce \& 265 McElreath 2018). Indeed, because members of different groups often live close together, particularly when population density is high, intergroup relationships will not necessarily provide access to less-correlated resourcesthis risk-management function is actually more charac- 270 
teristic of long-distance relationships than intergroup relationships.

Evidence suggests that both intergroup and longdistance relationships have long been features of human sociality. Members of the genus Homo likely had ties spanning distance by at least 300,000 years ago (Foley \& Gamble 2009), if not 500,000 to one million years ago (Layton et al. 2012); periodic aggregation (like seasonal meetings at productive resource patches,

280 Kelly 2007) might have reduced the cost of forming and maintaining these relationships. By the late Pleistocene, long-distance relationships appear to have been a central feature of human sociality (Foley \& Gamble 2009; Sterelny 2011; Singh \& Glowacki 2021). The movement 285 of durable goods - like stone, shells, and other materials that persist in the archaeological record-across tens to hundreds of kilometers provides supporting evidence; though these goods may have passed through multiple hands, researchers point to the movement of goods as evidence for social networks spanning large distances (Gamble 1999; Irwin et al. 2019; Foley \& Gamble 2009; Whallon 2006). If this interpretation of the archaeological record is correct, long-distance relationships may have become a central feature of human sociality earlier than intergroup relationships.

Turning to intergroup relationships, resources that are monopolizable - either because they are clumped in space (e.g., see Dyson-Hudson \& Smith 1978) or because groups can specialize in their production (e.g., see

300 Barth 1956) - are likely to be defended. When resources are both valuable and defensible, institutions promoting the acquisition and defense of these resources are likely to emerge in human populations (Barth 1998; Glowacki 2020), often leading to sedentism (Kelly 2007). Seden305 tism, in turn, increases the relevance of using identity markers to pick social partners, as it becomes difficult to keep track of individualized characteristics as population size grows (Smaldino 2019). Archaeologists often interpret stylistic decoration, such as that on pottery or bead-

310 work, as indicative of identity markers. In the archaeological record, movement of symbolically marked goods across space may thus reflect intergroup relationships (e.g., Braun \& Plog 1982; Irwin et al. 2019; Wiessner 1984), but may also indicate pillaging or the expansion of 315 identity groups - e.g., through conquest or colonization. In high-density, sedentary populations, an individual's valuation of members of different groups is often guided by generalizations (Tooby et al. 2006), extended to those that share the same ethnic markers (Smaldino 2019). In

320 short, ethnic groups, and thus intergroup relationships, likely became prevalent during the Pleistocene as sedentism became more prevalent (Sterelny 2016), perhaps as recently as 130,000 years ago (Singh \& Glowacki 2021). The use of religion as a marker of group identity (Sterelny 2018). However, the timing of the emergence of intergroup and long-distance relationships remains an active area of research.

\subsection{How might the choice of cooperative partners integrate information about location and group 330 membership?}

A person's location and group membership are just two of the many criteria that humans weigh when choosing social ties. Individuals often prefer partners with reputations for cooperativeness (Barclay 2013a; Smith \& 335 Apicella 2020), generosity (Smith \& Apicella 2020), and being a "good person" (Pisor \& Gurven 2018). Beyond cooperativeness, individuals often consider whether candidate partners have the means to help (Smith \& Apicella 2020) - e.g., if they hold wealth (Pisor \& Gurven 2018). 340 Additionally, individuals must consider what the market looks like - they must consider what alternative partners are available (Barclay 2013a). Group identity and location are thus just two additional criteria on which individuals may base decisions about social ties (Pisor \& 345 Gurven 2018; Pisor \& Surbeck 2019). Importantly, however, intergroup and long-distance relationships change the market by increasing the number of prospective partners; this may lead to tradeoffs in investment between close-distance and long-distance partners, or between 350 same-group and intergroup partners - a phenomenon that requires further research (Pisor \& Jones 2021).

\section{Differentiating intergroup relationships and long-distance relationships: A case study}

Intergroup relationships and long-distance relation- 355 ships have some non-overlapping functions and may have emerged at different times in human evolutionary history. However, because intergroup relationships are a primary focus of research on human sociality, long-distance relationships can be easily overlooked, or 360 intergroup relationships and long-distance relationships conflated - as author ACP can attest. While investigating whether opportunities for increased resource access favor intergroup relationships and reduce expression of parochial altruism, ACP came to recognize the impor- 365 tance of distinguishing between intergroup relationships and long-distance relationships.

To illustrate this distinction, we relate ACP's experience studying the two in rural Bolivia. Collecting survey, economic game, and ethnographic data among 370 three horticultural populations in 2014-2015 $(n=200)$, ACP found substantial variation in how ethnic and religious group boundaries impacted participants' preferences for forming social ties. Simultaneously, her ethnographic data suggested that long-distance relationships 375 played important roles in the lives and social networks of rural Bolivians. However, ACP found that capturing preferences for long-distance relationships was challenging. A forced-choice task $(n=120)$ deployed with two of the three populations underscored the relevance of multiple 380 criteria, including indicators of willingness and ability to cooperate, in partner choice-but participants did not express a preference for long-distance partners, likely due to methodological design. 
This case study offers a cautionary tale for scholars studying human sociality in non-WEIRD populations (Henrich et al. 2010): quantitative survey tools that (purportedly) work well in one context may not work in another (Hruschka et al. 2018). The failure of results to

390 generalize across protocols is only apparent when researchers deploy multiple methods to assess the same question.

\subsection{Ethnic groups, religious groups, and 21 st century rural Bolivia}

ACP first decided to study intergroup relationships in Bolivia because of the effects of recent changes in government policy. In the 1980 s, 1990 s, and early 2000 s, Indigenous groups in Bolivia banded together in largescale movements pushing for Indigenous rights. At long last, in the late 2000s, the Bolivian central government came to recognize the sovereignty of 36 different pueblos indigenas. ${ }^{1}$ Despite the new rights extended to these pueblos indigenas, the state preferentially allocates its limited funds to Indigenous communities that are also 405 originarios-living on their traditional lands. Because of this, what was a shared identity of indigeneity in the 1980s-2000s has now splintered as different Indigenous communities, originarios and otherwise, compete with one another for government resources and recognition (Fontana 2014).

Religious denominations can also delineate group boundaries in rural Bolivia. Evangelical churches of various denominations are expanding their presence in Bolivia (Gill 1993), as elsewhere in Latin America (Stoll 415 1990): as of 2019, approximately $18 \%$ of Bolivians identified as "Christian" or "Evangelical" rather than "Catholic" (Siete 2019). Rural Bolivians candidly contrast Catholic and Evangelical beliefs, distinguishing what "we" do from what "they" do.

In the midst of these changes to ethnic and religious identities, market participation is on the rise among rural Bolivians. Households increasingly rely more on cash income and less on subsistence production to fulfill their needs (Gurven et al. 2015; Reyes-García et al. 2010). With increased market participation comes increased mobility, contact with middlemen, and exposure to individuals of other pueblos indigenas and individuals who live far away (Pisor \& Jones 2021).

Adopting the assumption that parochial altruism structures intergroup relations, ACP set out to study whether variation in the incentives for intergroup relationships - in Bolivia, between pueblos indigenas or across the Catholic/Evangelical divide — could affect preferences for intergroup relationships. She predicted

\footnotetext{
1 Pueblos indigenas are specifically defined as Indigenous groups whose members are originarios-living on their traditional lands - and whose members share cultural institutionsexplicitly recognized by the government as their usos y costumbres. This definition makes "pueblo indigena" akin to the definition of "ethnicity" used in the evolutionary anthropology literature (e.g., McElreath et al. 2003; Moya \& Boyd 2015; Bunce \& McElreath 2017).
}

that individuals with fewer resources might show more 435 interest in building intergroup relationships in order to gain resource access (Pisor \& Gurven 2016, 2018). This prediction was partially supported. However, ACP failed to appreciate the distinction between intergroup relationships and long-distance relationships.

\subsection{Collaborating communities}

Three populations of Bolivian horticulturaliststhe Mosetén people, the Tsimane' people, and the Interculturales - are the focus of the present study. The Mosetén and Tsimane' are pueblos indígenas, recog- 445 nized by the Bolivian government as originarios because they live on their traditional lands. Mosetén and Tsimane' have lived in the lowlands for centuries (Godoy 2015; Huanca 2008), and the two groups were once a continuous, intermarrying population (Godoy 2015; Gur- 450 ven et al. 2007; Ringhofer 2010; Bert et al. 2001; Sakel 2011).

Today, however, their lives are quite different. While the Mosetén were missionized by Franciscan Catholics during the 19th century (Godoy 2015; Mamani \& 455 Huasna Bozo 2010; Nordenskiöld 2001), the Tsimane' were missionized in the 20th century by Evangelical Christians (Huanca 2008). Efforts by missionaries resulted in access to roads and secondary education for most Mosetén communities by the year 2000 (Pisor \& 460 Gurven 2018); in contrast, only a minority of Tsimane' communities have access to major roads or secondary schooling (Ringhofer 2010). The Mosetén have more years of education, participate more in the market economy, and have higher mobility than do the Tsimane'. To- 465 day, while the Mosetén speak fluent Spanish, the lingua franca of Bolivia, and intermarry extensively with other pueblos indigenas (Pisor \& Gurven 2018), only 14\% of the Tsimane' speak fluent Spanish (Pisor \& Gurven 2016) and few have intermarried with other pueblos indí- 470 genas. That said, Tsimane' individuals maintain far-flung connections with other Tsimane', solidified through visitation, migration, and marriage.

The Interculturales are also a community of Indigenous descent; however, they are not considered originar- 475 ios and accordingly are not eligible for special government recognition and resources. The word intercultural is a designation used by the Bolivian government to recognize communities who are no longer on their traditional lands or who are composed of members of differ- 480 ent pueblos indígenas (Albó \& Suvelza 2007). The Intercultural community discussed here is composed primarily of descendants of the Aymara and Quechua pueblos indigenas. These groups were incentivized to move to the area by government relocation programs in the 1950s- 485 $60 \mathrm{~s}$ and by booms in the logging and quinine industries (Pisor \& Gurven 2016, 2018). Upon arrival, many Interculturales learned horticulture for the first time, sometimes by copying the Mosetén. However, they retained many Aymara-influenced institutions, especially with re- 490 spect to social and political organization. The Interculturales are more reliant on the market economy than are 
the Mosetén: they have had reliable access to roads for 25 years longer (Llojlla Roca 2011) and they began to build economic relationships with middlemen much earlier (Pisor \& Jones 2021). On average, Interculturales have as much education as Mosetén, but slightly higher incomes, more market possessions, and higher mobility.

\section{Measuring interest in intergroup relation- ships}

Consistent with her expectations that parochial altruism structures intergroup relations and that group boundaries would be especially salient in Bolivia, in 2014 15, ACP and Michael Gurven set out to study the predictors of preferences for intergroup relationships. They used an economic game that they designed-the nonanonymous giving game (NAGG) - to assess how much participants preferred in-group partners at the expense of out-group partners and vice versa (Pisor \& Gurven 2016,

510 2018; Pisor \& Ross 2021). $\mathrm{ACP}^{2}$ presented each participant with photos of six strangers, three from their same pueblo indigena or religious affiliation and three from a different one ${ }^{3}$. She told participants the first name, age, and either the pueblo indigena or religious affiliation of each stranger. ACP then placed three coins (each worth \$0.14 USD; total stakes: $1 / 3$ of a day's wages) on each photo and three coins in front of the participant. She indicated that the participant could move any coins they wished, or leave the coins as they were, and that any coins left on a photo would be given to the corresponding person in the participant's name, while any coins that the participant left in front of themselves would be theirs to keep. Games like this, in which participants are not asked to think about existing real-world relationships or situations, provide more insight into participants' private preferences - how they would behave if they could. In this case, the game measured preferences for a generous transfer in an experimental context, rather than realworld behavior (Pisor et al. 2020), a point we return to below. For further details on the NAGG, see Pisor \& Gurven $(2016,2018)$.

Consistent with their prediction that interest in resource access would increase interest in intergroup relationships, reducing parochial altruism, ACP and Gurven 535 found that Mosetén, Intercultural, and Tsimane' participants who felt that they were less well-off than others in their community were more likely to give money to out-group strangers (Pisor \& Gurven 2016). Similarly, Tsimane' participants who had fewer market possessions than other Tsimane' participants also gave more to outgroups strangers (Figure 1a). Though participants gave more to in-group members than to out-group members on average, mean out-group giving was far from zero: $82 \%$ of participants gave at least some money to out-

\footnotetext{
${ }^{2}$ Research assistant Bernabe Nate Añes was integral to data collection among the Tsimane'.

${ }^{3}$ In this rural context, strangers by definition live at a distance; as communities rarely exceed 1,000 people, local individuals are known.
}

group members (Figure 1b). That said, participants were 545 not uniform in their out-group giving.

First, Tsimane' preferences looked quite different from Mosetén and Intercultural preferences. Tsimane' participants were generally far less likely to give any money to individuals of other pueblos indigenas or re- 550 ligious affiliations ${ }^{4}$ (Figure $1 \mathrm{~b}$ ). It is possible that Tsimane' participants valued the money in the game more: the Tsimane' have less wealth on average than the Mosetén or Interculturales and see themselves as "havenots" relative to others pueblos indigenas (Pisor \& Gur- 555 ven 2018; Pisor \& Ross 2021).

Second, participants used qualities other than a recipient's group membership in decision-making. After completing the game, participants - especially Mosetén and Intercultural participants - described inferring recip- 560 ient characteristics from their photos, including their relative need and whether they were a good person, and using those characteristics to make decisions about giving (Pisor \& Gurven 2018; Pisor et al. 2020; Pisor \& Ross 2021).

These differences in generosity toward out-group members are perhaps unsurprising: the Tsimane' have less exposure to members of other pueblos indigenas than do the Mosetén or Interculturales. While some of this reduced exposure among the Tsimane' is due to con- 570 strained mobility (given the few passable roads and the expense of gasoline for river travel) and limited access to education (there are few fluent Spanish speakers), some is also due to active avoidance of out-group members. At the time of European contact, the Tsimane' were well- 575 known among other Indigenous groups in the region as salt traders (Godoy 2015; Nordenskiöld 2001). However, their interactions with highland Bolivians (collas) and non-Indigenous lowland Bolivians (cambas) have been marked by misunderstandings, marginalization, and dis- 580 crimination; the Tsimane' have retreated from contact with the Spanish and cambas when these groups took advantage of them (Godoy 2015; Ringhofer 2010; Huanca 2008).

\section{Conflating two questions}

Although market participation is increasing for all three populations, none are interacting with other pueblos indigenas for the first time. As aforementioned, the Tsimane' were renowned salt traders at the beginning of the 20th century: salt in the Amazon is heavily con- 590 centrated in certain areas (Reeve 1993), creating a demand for long-distance trade. The Mosetén have long traded with lowland groups for tools, medicine, and plants (Lathrap 1973; Ringhofer 2010), and, centuries ago, traded with the Inka for metal goods (Godoy 2015). 595 Before Columbus, the Quechua and Aymara, whose de-

\footnotetext{
4 Note that at the time of data collection, most Tsimane' were affiliated with the same Evangelical church, such that recipients of the same religious affiliation were frequently also Tsimane' - and Tsimane' participants could easily tell who was Tsimane' from looking at the photos (Pisor \& Gurven 2018).
} 

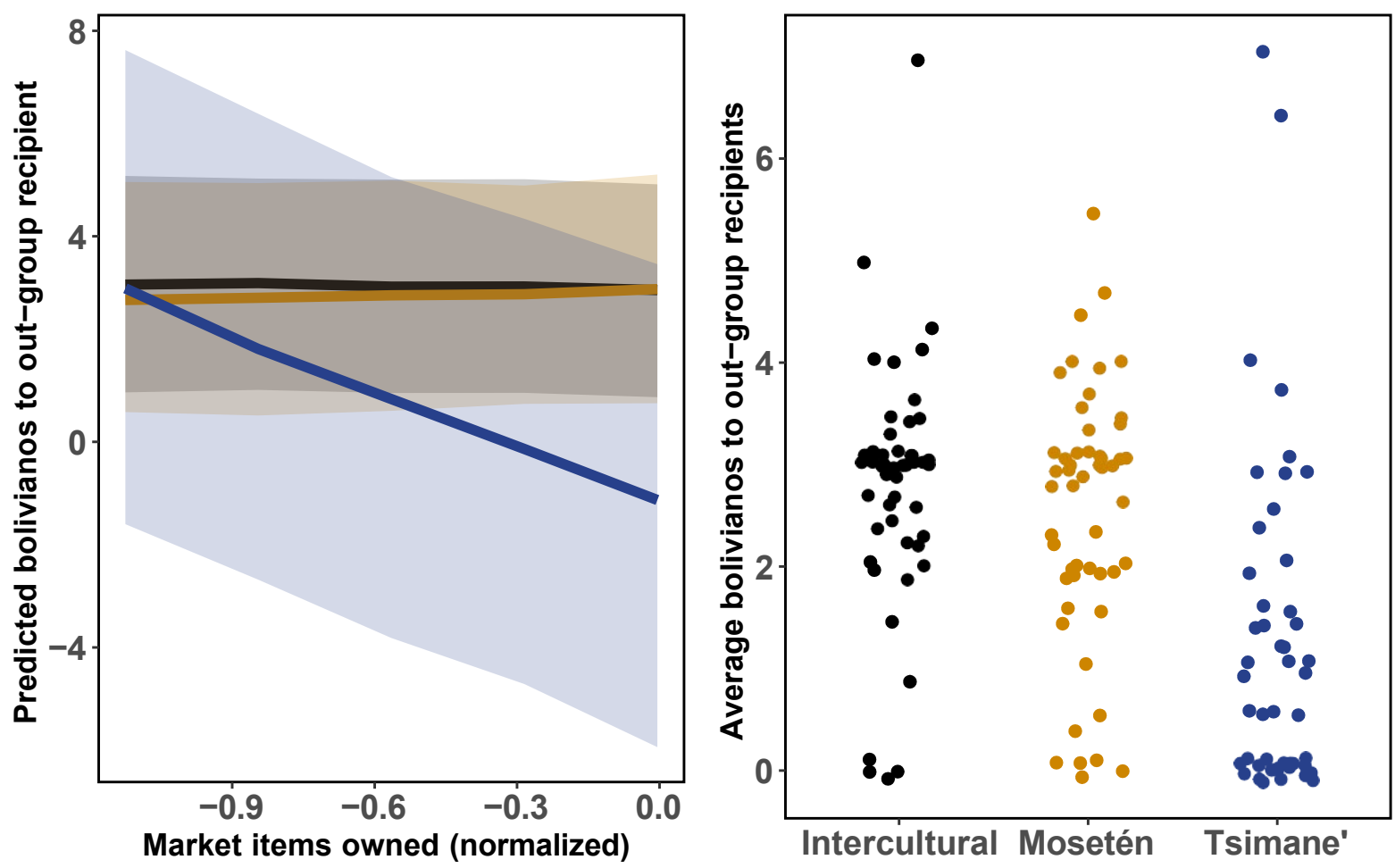

Fig. 1: (A) Predicted bolivianos, the local currency in Bolivia, given by a participant to an out-group stranger as a function of the total estimated value of market items owned by the participant, normalized relative to other participants in the same population (Pisor \& Gurven 2016, 2018). The shaded areas are the 90\% credible intervals. Predictions for Intercultural participants are in black, Mosetén in orange, and Tsimane' in blue. For details on this model, see SI Section 1.3. (B) Average bolivianos given by a participant to an out-group stranger (that is, an individual from another pueblo indigena or with a different religious affiliation) in the NAGG (Pisor \& Gurven 2016, 2018). The initial allocation was 3 bolivianos per recipient. Points are jittered.

scendants are residents of the Intercultural community, had trade networks spanning the Andean ecozones, ensuring access to foods from different regions (Klein 2011). Importantly, members of these networks were often members of the same ethnic group.

The common characteristic of these connections is not that they span group boundaries, but that they span distance. ACP had assumed that intergroup relationships were consonant with distance. However, it is longdistance relationships, not intergroup relationships, that are especially likely to help individuals diversify their resource access across geographic space; different groups may live close together, for example, as the Intercul610 turales and Mosetén do. ACP had not even thought to investigate whether individuals with less resource access would be more interested in long-distance relationships. Once she realized her oversight, she returned to the Mosetén and Intercultural communities in 2017 to revisit how individuals were using social connections to access non-local resources - this time using methods that she hoped would distinguish between preferences for intergroup relationships and long-distance relationships.

\section{The reality of long-distance relationships}

Though long-distance relationships can function to both buffer local shortfalls and provide access to resources not locally available (Section 1.2), ethnographic and survey evidence suggest that for the Interculturales and Mosetén, they are more important for accessing unavailable resources than buffering shortfalls. In 2014, 625 much of lowland Bolivia was hit with severe flooding. Landslides destroyed roads serving the Mosetén and Intercultural communities and cut power and cell service for more than a month. Because are one of the most common natural disasters in Bolivia (World Bank 2020), both the Mosetén and Interculturales have cultural practices for managing the risk of resource shortfalls due to flooding, including raising pigs and chickens that can be slaughtered during hard times, and the Interculturales have a system of loaning rice. In 2014, families ate their 635 pigs, chickens, and rice. Once these fallback foods were depleted, the Mosetén marched down their destroyed road to demand support from the municipal and federal governments. Both the Intercultural and Mosetén communities eventually used motorized canoes to ferry emer- 640 gency supplies - mostly food and medicine-from the 
local town. When waters receded, the municipal government sent equipment and laborers to repair the roads. Mosetén and Intercultural families who could not absorb the cost of their destroyed crops sought loans from local banks.

Long-distance relationships were not central to household responses to the 2014 flood. Because landslides had severed roads and communications, individuals could not contact their long-distance connections. Instead, resources that could buffer the local shortfall came from the government and from banks. This is not an unusual pattern: in many rural contexts, government entities, international organizations, and banks can take the place of social connections for managing risk (Pan 2009). Given the limited role of long-distance relationships in 2014, it is perhaps unsurprising that three years later, when asked who would help them with a loan during a hypothetical flood, Mosetén and Intercultural participants were more likely to name same-community individuals or government entities than connections living at a distance (Figure 2a) (Pisor \& Jones 2021).

Though they may not be an important source of risk buffering for the Mosetén and Interculturales, longdistance relationships are crucial for access to resources not locally available (Pisor \& Jones 2021). First, both communities rely on middlemen - often based in the capital city of La Paz (seven hours away by car) - to purchase their crops. Second, both increasingly engage 670 in migrant labor to supplement their incomes. Longdistance relationships are key to finding work as a migrant laborer. For example, when asked who they would contact for a "good job that pays well," $65 \%$ of participants named an individual or entity outside of their com-

675 munity (Figure 2b). Third, market participation provides cash income, which translates into increased mobility. The Mosetén and Interculturales increasingly have business in La Paz and send their children to university or job training programs there. Individuals report that $\mathrm{La}$

680 Paz residents help them navigate local bureaucracy, from completing government paperwork to enrolling in universities. Further, given the high cost of lodging in La Paz, city residents can provide low-cost shelter. Fourth, long-distance relationships provide access to goods only 85 available in the city. For example, La Paz residents frequently send parcels, or encomiendas - which can contain anything from bread to cell phones or televisionsby bus to rural residents.

The Mosetén and Interculturales have various means for maintaining their long-distance relationships (Pisor \& Jones 2021). Reciprocal exchanges of encomiendas are common: residents of $\mathrm{La} \mathrm{Paz}$ often request fresh produce like plantains and mandarin oranges, which are expensive in the city. Community members also send 695 and receive money transfers, or giros; giros may be used to reimburse someone for an expensive encomienda or to loan money. Semi-reliable cell phone service has been available to the Mosetén and Interculturales since 2010. Phone calls, and increasingly, WhatsApp or Facebook Messenger, are used to maintain contact with long- distance relationships. Visitation remains important to relationship maintenance as well: depending on an individual's means, they may take buses, shared taxis, or their own vehicles to visit long-distance relationships, often for several days.

\subsection{Who are these long-distance connections?}

Intercultural and Mosetén community members maintain long-distance relationships with both relatives and non-relatives. Unsurprisingly, many are consanguineal or affinal kin (Pisor \& Jones 2021). However, 710 Mosetén and Intercultural Catholics also strategically use fictive kinship - namely, godparent relationships (compadrazgo) - to solidify long-distance relationships with individuals they believe are wealthy or influential enough to help them or their children (Mintz \& Wolf 1950). In- 715 dividuals who are from $\mathrm{La} \mathrm{Paz}$ and spend time both in the community and in the city are favorite choices, especially teachers, doctors, and middlemen. Long-distance relationships are also forged during periods of temporary migration: for example, during stints of migrant labor, 720 while studying at university or in career programs, or, for men, while completing military service.

When individuals have long-distance relationships with non-kin, however, they often do not know the pueblo indigena of their social partner. In 2017, ACP 725 asked participants to identify the pueblo indigena of their long-distance relationships. Participants had a difficult time understanding the question; ACP often cycled through several phrases - pueblo indigena, descendencia (descent), parentezco (kinship) — or gave examples be- 730 fore a participant was able to answer. Once they understood the question, participants often guessed when responding. Some identified all friends from the lowlands as cambas, even though Indigenous peoples are also from the region; others reasoned that if someone lives in $\mathrm{La} 735$ Paz, they must be Aymara, the dominant pueblo indigena in the city.

In short, the pueblo indigena of a long-distance relationship was far less salient to participants than might be expected given the political landscape in Bolivia. It was also far less salient than we might predict given how much sway ethnicity is given in the evolutionary anthropology and evolutionary psychology literatures. See Moya \& Boyd (2015) for a similar example from Perú.

\section{Focusing on intergroup relationships can 745 mask the importance of long-distance rela- tionships}

Given the wealth of ethnographic and self-report evidence that long-distance relationships are important to the Mosetén and Interculturales, ACP set out to design a 750 task that could potentially distinguish participants' preferences for long-distance relationships from their preferences for intergroup relationships. Though individuallevel differences in resource access may predict differential investment in long-distance relationships, ACP was 755 also aware that participants with less wealth may have 

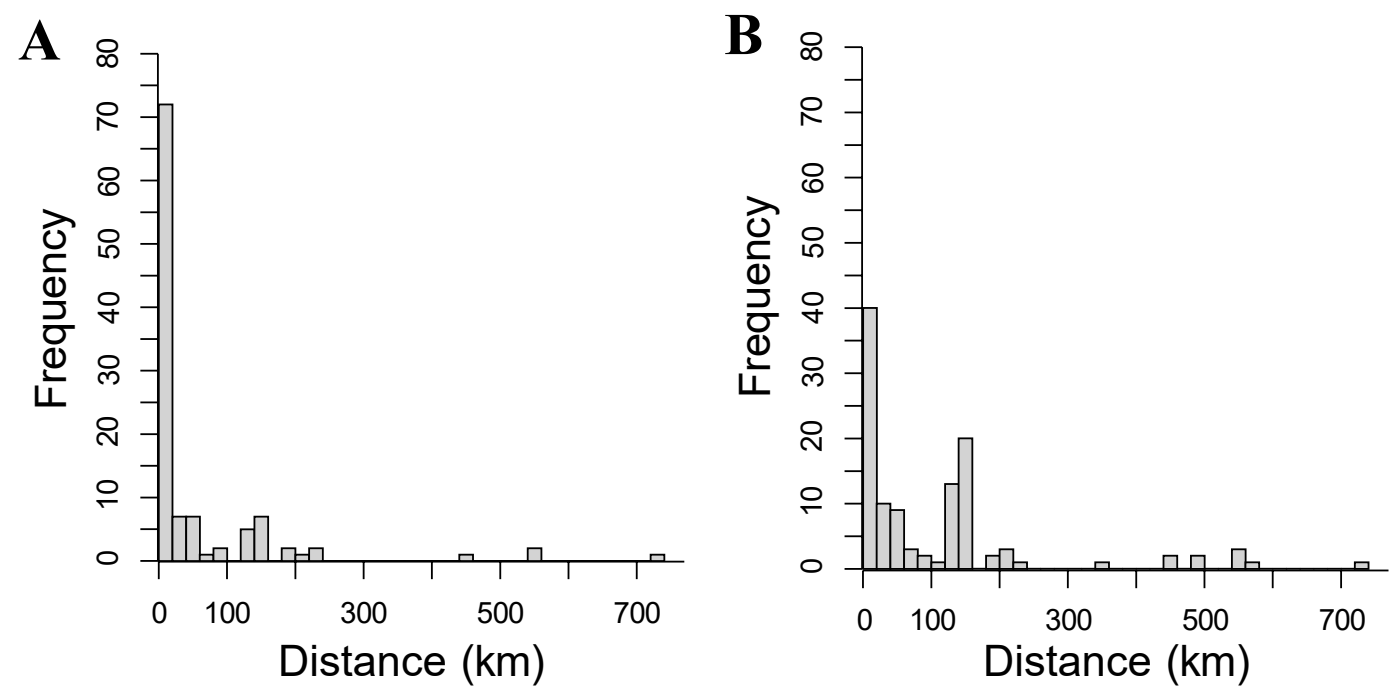

Fig. 2: Each participant was asked to name someone who could help them (A) with a loan of 500 bolivianos ( $\$ 70$, or 8 days' wages) if a flood destroyed their crops, and (B) find "a good job that pays well." Most participants named individuals, but some named government entities, organizations, or private companies. Counts reflect the distance between the participant and where these named individuals or entities were located.

had more incentive to keep money for themselves in the 2014-2015 economic game. She reasoned that a task not involving money might reveal preferences for forming new social relationships independently of preferences for giving or keeping money. Drawing on marketing research, she chose a paired-comparison forced-choice task (see Rao et al. 2014) to assess which traits participants preferred in candidate friends.

ACP presented participants with pairs of cards representing hypothetical individuals, each described by six categories of characteristics (SI Figure 1), and asked which of the two cards they would prefer as a new same-sex friend. In addition to the location of the candidate friend, their pueblo indigena, and their religious affiliation, three other categories of characteristics were included - trustworthiness, being a "good person" (buena gente), and wealth - as these characteristics were some of the most frequently mentioned during the NAGG game played in 2014-15 (Pisor \& Gurven 2018).

Participant preferences in the choice task, however, did not reflect the documented prevalence of longdistance relationships in these communities (Section 5). Participants preferred candidate friends of their own pueblo indigena and religious affiliation (Figure 3). They also had a slight, though inconsistent, preference for friends from their same community over friends from other places.

Why the discrepancy between the behavioral data reported in Section 5 and the preferences elicited by the choice task? Some participants reasoned aloud during the decision-making process, providing insight (Bernard 2017). These participants would often identify one characteristic of the six that stood out to them ("this one is from my church, so I pick him") and continue to make decisions based on that criterion across all pairs of cards. In other words, even though characteristics of candidate friends varied across cards, participants stopped attending to characteristics other than the one they initially selected.

Not only did participants' preferences in the choice task not reflect the real-world importance of longdistance relationships, they did not reflect the preferences elicited by the 2014-2015 NAGG game either. Recall that in the game, despite some preference for in-group 800 members, there was substantial out-group giving. In total, 63 participants completed both the 2017 choice task and the 2014-2015 game. There was no relationship between participants' preferences in the 2014-2015 game and their preferences in the 2017 choice task (see SI Sec- 805 tion 3). Perhaps this reflects real changes in preferences over time-possibly related to changes in political climate or in material wealth. However, it is likely that differences in methodological design also play a role.

\subsection{Methodological design: A cautionary tale}

There are several reasons why participants may have used pueblo indigena membership as a rule of thumb for choosing social partners in the choice task. First, rules of thumb can ease the cognitive burden of repeated decision-making. If pueblo indigena membership 815 was made salient by the design of the task, participants may have first looked for differences in membership between the two candidate friends and, if a difference was present, used it for decision-making (i.e., a "take-thebest" heuristic; Gigerenzer \& Goldstein 1996). Partici- 820 pants may especially lean on heuristics when they find tasks tedious (e.g., Tucker 2017), as they did in this study. 


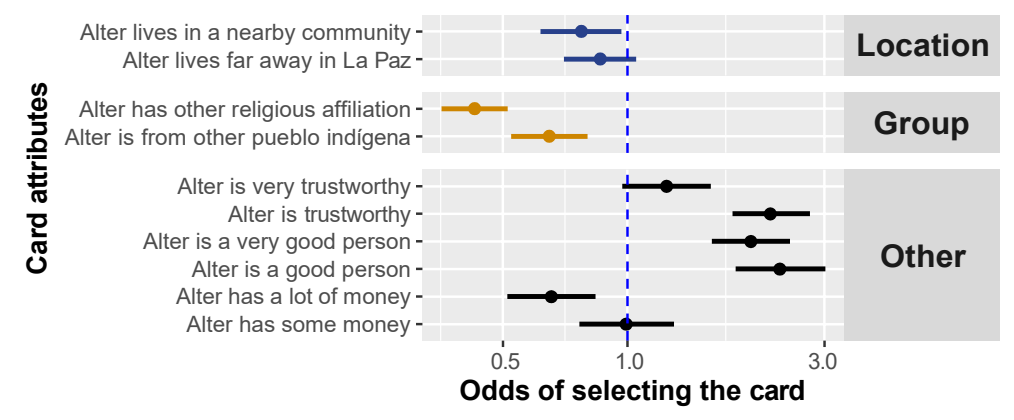

Fig. 3: Each participant $(n=125)$ was presented with a pair of hypothetical individuals and was asked which they preferred as a new friend. Each evaluated 18 pairs of individuals. Here, we present non-standardized estimates (means and $90 \%$ credible regions) from a logistic regression; these estimates reflect the odds of selecting one individual if it were to differ by only a single attribute from the other individual. The base case is a candidate friend who lives in the same community, is from the same pueblo indígena and has the same religious affiliation, and who is not good, not trustworthy, and has no money. The estimates indicate that participants preferred a same-community friend over more distant friends, same-ethnic and same-religious group friends over those from other groups, and friends that are "good people," trustworthy, and —interestingly—not excessively wealthy.

Second, with so few categories of friend qualities (here, six total), demand characteristics or experimenter effects are a concern. Perhaps participants intuited that ACP was interested in group membership, especially since that was how she framed her research in 2014-2015 when talking to community members (Nichols \& Maner 2008). In other words, if researchers are strongly focused

830 on group membership, they can inadvertently increase the salience of group boundaries - even for groups that are not particularly salient locally — and thus alter their research findings.

Third, when features of the real world are removed and partner choice is based only on a list of characteristics, group boundaries may be more salient than they are in real-world partner choice. Cueing identity can shift elicited preferences (Benjamin et al. 2010).

Fourth, there is not a one-to-one mapping between 840 preferences and behavior (Pisor \& Ross 2021; Pisor et al. 2020). Even if this task were measuring what it was designed to measure- and the foregoing gives us reason to doubt this - participant preferences can be eclipsed by real-world constraints and incentives, leading to a disconnect between "cheaply elicited" preferences and behavior in the real world.

For similar discussions of how preferences elicited by experimental tasks can differ from the real world, and why field researchers should use multiple methods

850 to triangulate the reality of preferences and behavior, see (Tucker 2017; Hruschka et al. 2018; Pisor et al. 2020).

\section{Discussion}

Intergroup relationships and long-distance relationships are two different features of human sociality with partially overlapping functions. Given the high costs of intergroup conflict and its sequelae, researchers often focus their attention on how intergroup relationships can defuse conflict - usually between ethnic groups. However, intergroup relationships and long-distance relation- ships may have emerged at different points in human evo- 860 lutionary history and may be products of different selection pressures. Long-distance relationships can span distance without crossing group boundaries, providing access to resources that are not available to an individual's local social partners or that are less correlated with lo- 865 cally available resources. While intergroup relationships can also offer access to resources not locally available, especially when different groups specialize in producing different resources, intergroup relationships are distinct in that they can also be strategically used to reduce 870 intergroup conflict. In short, researchers can ask separate questions about intergroup relationships and longdistance relationships, including why one may be common in a given context while the other is not.

Drawing on a case study from Bolivia, we illustrated 875 the importance of distinguishing intergroup relationships from long-distance relationships. As ethnic groups, or pueblos indígenas, are central to contemporary Bolivian discourse and compete with one another for government resources, author ACP expected that in rural Bolivia, eth- 880 nic group boundaries would be salient, parochial altruism common, and any intergroup relationships noteworthy. However, in three populations located within 50 miles of each other, intergroup relationships varied in both their prevalence and their salience.

For the Tsimane', long-distance relationships are more common than intergroup relationships. The area the Tsimane' inhabit is large (the land to which they hold title alone measures 4,013,228 square kilometers; Ringhofer 2010), population density is low, and few 890 non-Tsimane' live in Tsimane' territory. Accordingly, strangers, whether in-group or out-group, live at a distance and long-distance relationships with other Tsimane' are common. However, the distance between the Tsimane' and other ethnic groups is not an exoge- 895 nous variable: due to a long history of inequality and discrimination, the Tsimane' have retreated from con- 
tact with other groups (Godoy 2015; Ringhofer 2010; Huanca 2008). Perhaps unsurprisingly, in an economic game designed to gauge interest in forming new relationships, Tsimane' participants preferentially invested in Tsimane' strangers - by definition, individuals living at a distance - rather than strangers from another ethnic group (Figure 1; Pisor \& Gurven 2016, 2018).

In contrast, in a Mosetén community and an Intercultural community, intergroup relationships are ubiquitous and long-distance relationships very common. Both communities are also rural, so strangers live at a distance; however, mobility and intermarriage between eth-

910 nic groups are much higher than among the Tsimane'. Accordingly, for the Mosetén and Interculturales, the discrepancy between in-group and out-group giving in the non-anonymous giving game was less than observed among the Tsimane', consistent with the pervasiveness

915 of intergroup relationships (Figure 1; Pisor \& Gurven 2016, 2018). Long-distance relationships are ubiquitous too-important for selling crops, finding jobs, and navigating the capital city, from getting lodging to managing bureaucracy. Asked to name who they would contact for

920 a "good job that pays well," $65 \%$ of participants named an individual or entity outside their community (Figure 2b).

As we have highlighted here, we should not be surprised that preferences for intergroup relationships vary across participants and communities. First, despite focus on ethnic groups in evolutionary approaches to human behavior, not all groups are ethnic groups (Pisor \& Ross 2021); if ethnic group boundaries do not structure cooperation - as is largely the case for the Mosetén and

930 Interculturales, but notably not for the Tsimane'-they will be less salient to individuals (Moya \& Boyd 2015). Second, valence and valuation matter; for Tsimane' participants, intergroup interactions are often characterized by a negative valence-given past experiences of misunderstandings, marginalization, and discriminationand the expected value of intergroup ties is likewise low. In general, we should expect an individual's interest in intergroup relationships to track the expected net benefits of such relationships (Pisor \& Gurven 2018).

940 These net benefits will be impacted by the relevance of group boundaries for cooperation and by past experiences with out-group members, among other criteria. Likewise, the expected net benefits of long-distance relationships should influence partner choice; we expand on

\subsection{Long-distance relationships: Improving method- ological design}

Though ACP designed a task to tease apart partner preferences based on group membership and location, she found that ethnographic data on long-distance relationships were surprisingly hard to corroborate through simple experimental tasks. The forced-choice task did underscore that partner choice is often based on characteristics pertinent to cooperation, like willingness or abil-
\& Gurven 2018) - location is just one of many partnerchoice criteria. It also underscored that the salience of group membership can be primed by empirical methods (e.g., Pisor et al. 2020), as suggested by the lack of correspondence between participants' allocations in the 960 non-anonymous giving game and their decisions in the forced-choice task.

Our case study serves as a cautionary tale, with lessons for how can researchers better measure longdistance relationships going forward. Given that long- 965 distance ties are often not as salient as local ties (Wobst 1978), asking about them directly is more fruitful than hoping they will turn up in experimental tasks with little demonstrated external validity. ACP, her collaborators Kristopher Smith and Monique Borgerhoff Mulder, and 970 their team ask about long-distance friendships directly in their ongoing research in Tanzania; thus far, they find this approach appears to have good face validity - that is, it appears to actually measure what it is supposed to measure.

\subsection{Long-distance relationships: Future directions}

As we demonstrated here, while intergroup relationships and long-distance relationships have overlapping functions, they are distinct types of relationship and vary in their prevalence, even between nearby communities. 980 The focus on intergroup competition in the social sciences tends to make intergroup relationships noteworthy and to mask other features of human sociality, like the importance of long-distance relationships in human social life over the last 300,000 to 1 million years (Foley \& 985 Gamble 2009; Layton et al. 2012).

To better characterize the structure and importance of long-distance relationships, we recommend the following avenues for further research:

- Where and when will long-distance relationships be 990 more common? As outlined here, we should expect long-distance relationships to be more common where and when: (i) resource shortfalls can strike entire communities, and (ii) key resources cannot be obtained locally. Long-distance relationships 995 can be especially important when shortfalls regularly strike entire communities-when shortfalls are predictable in their recurrence (Pisor \& Jones 2021) - and when government support is absent or unreliable (Pan 2009). Climate variability can 1000 increase the frequency and duration of shortfalls, so in the absence of sufficient government support, we can expect long-distance relationships to become even more important given contemporary, anthropogenic climate change (Pisor \& Jones 2021; 1005 Jones et al. 2021). With respect to non-local resource access, archaeological data offer a classic example of long-distance relationships: artifacts provide evidence of how non-local resources were obtained through long-distance exchange networks 1010 (Lathrap 1973; Spielmann 1986; Braun \& Plog 1982; Irwin et al. 2019). Even in countries today 
where online platforms offer fast access to non-local resources, from job postings to at-home delivery, long-distance relationships continue to be a crucial source of fiscal resources (e.g., remittances) and word-of-mouth information (Pisor \& Surbeck 2019).

- How are long-distance relationships maintained? Do they have the same characteristics as shortdistance relationships? Research on long-distance relationships has traditionally focused on relationships formed when two individuals live in the same place, and then one moves away (Poli1025 carpo 2016). Long-distance relationships are often characterized by commitment, mutual trust, and seeking the advice of one another, but compared to short-distance relationships, commitment to long-distance relationships varies more across time (Johnson et al. 2009). But what about long-distance relationships forged between two individuals who have never lived in the same place - do individuals pick long-distance friends using the same criteria they use to choose short-distance friends? Further, do the strategies individuals use to maintain long-distance relationships forged from a distance look like those used to maintain relationships that start local and become long-distance relationships? More research is needed to address both questions.

- What are the consequences of long-distance relationships for cooperation? Existing theoretical work suggests that individuals may penalize in-group members for forging intergroup relationships if these endanger the effectiveness of within-group cooperation (Bowles 2008). However, when an individual forges a relationship that spans group boundaries (Fearon \& Laitin 1996) or distance (Fitzhugh et al. 2011), this can also generate benefits for in-group members or neighbors. Consider, for example, the cooperation required to manage large common-pool resources like fisheries, watersheds, grasslands, and forests, accessible by multiple communities. To avoid depleting these resources, members of the communities must not only avoid overharvesting, but also coordinate in setting and enforcing management rules (Varughese \& Ostrom 2001). Are individuals with long-distance relationships that span the boundaries of these communities less likely to overharvest and more likely to actively contribute to resource management? ACP, Smith, Borgerhoff Mulder, and colleagues have research underway designed to answer this question.

\section{Conclusion}

Intergroup relationships are a central focus of social science research, and rightly so: intergroup relationships offer a solution to the high costs of intergroup conflict (Dovidio et al. 2003; Pettigrew \& Tropp 2006; Brewer 2010; Riek et al. 2006). However, studying intergroup relationships to the exclusion of long-distance relationships, or even conflating the two, means that our research questions and data analysis may be imprecise, and our characterization of human sociality may thus be incomplete. We have presented a case study from rural Bolivia that emphasizes this point: after initially conflating the intergroup relationships and long-distance relation- 1075 ships, author ACP realized that long-distance relationships were more crucial to securing non-local resource access than were intergroup relationships per se. Longdistance relationships were also harder to study using standard quantitative methods; the mixed-methods find- 1080 ings we presented here underscore the importance of field-validating the methods we use to study human sociality.

The importance of studying long-distance relationships is not limited to the theoretical. If archaeolog- 1085 ical, ethnographic, and historical data are any indication, in the absence of sufficient government support, long-distance relationships may become an increasingly central part of individuals' responses to climate change (Pisor \& Jones 2021; Jones et al. 2021). Additionally, 1090 long-distance relationships may improve the effectiveness of management for large natural resource areas accessible by multiple communities. In sum, improving our understanding of when and how contemporary peoples use long-distance relationships has broad relevance.

\section{Conflict of interest}

The authors declare no conflict of interest.

\section{Biographical sketches}

Anne Pisor is an assistant professor of cultural and evolutionary anthropology at Washington State Univer- 1100 sity in the US. She combines evolutionary social science and applied anthropology to study the evolution of human social relationships and their relevance for two urgent issues of the 21 st century: climate change and resource conservation. Beyond Bolivia, she is also involved 1105 in research in Tanzania, Chile, and the US.

Cody Ross is a co-leader of the STRAND research group in the Department of Human Behavior, Ecology and Culture at the Max Planck Institute for Evolutionary Anthropology in Leipzig, Germany. He works on the de- 1110 velopment of tools for social network data collection and analysis, and manages a network of field sites in Colombia as part of the ENDOW project, which seeks to study the coevolution of network structure and wealth inequality longitudinally and cross-culturally.

\section{References}

Albó, X. \& Suvelza, F. X. B. (2007). Por una Bolivia plurinacional e intercultural con autonomías volume 22. PNUD La Paz.

Balliet, D., Wu, J. \& Dreu, C. K. W. D. (2014). Ingroup Favoritism in Cooperation: A Meta-Analysis. Psychological Bulletin. Psycholog- 1120 ical Bulletin Ingroup Favoritism in Cooperation,

Barclay, P. (2013a). Strategies for cooperation in biological markets, especially for humans. Evolution and Human Behavior, 34, 164 175.

Barclay, P. (2013b). Strategies for cooperation in biological markets, 1125 especially for humans. Evolution and Human Behavior, 34, 164 175 . 
Barth, F. (1956). Ecologic relationships of ethnic groups in Swat, North Pakistan. American Anthropologist, 58, 1079-1089.

Barth, F. (1998). Ethnic groups and boundaries. Waveland Press.

Benjamin, D. J., Choi, J. J. \& Strickland, A. J. (2010). Social identity and preferences. The American economic review, 100, 1913-1928.

Bernard, H. R. (2017). Research methods in anthropology. Rowman \& Littlefield.

1135 Berry, J. W. (2001). A Psychology of Immigration. Journal of Social Issues, 57, 615-631.

Bert, F., Corella, A., Gené, M. et al. (2001). Major mitochondrial DNA haplotype heterogeneity in highland and lowland Amerindian populations from Bolivia. Human Biology, 73, 1-16.

Bird, D. W., Bird, R. B., Codding, B. F. et al. (2019). Variability in the organization and size of hunter-gatherer groups: foragers do not live in small-scale societies. Journal of Human Evolution, 131, 96-108. Publisher: Elsevier Ltd.

Böhm, R., Rusch, H. \& Baron, J. (2020). The psychology of intergroup conflict. Journal of Economic Behavior and Organization, 178, 947-962.

Bollig, M. (2010). Risk management in a hazardous environment volume 2. Springer Science \& Business Media.

Bowles, S. (2008). Conflict: Altruism's midwife. Nature, 456, 326327.

Bowles, S. \& Choi, J.-K. (2001). The co-evolution of love and hate. University of Siena Working Paper, 401.

Bowles, S. \& Gintis, H. (2004). Persistent parochialism. Journal of Economic Behavior \& Organization, 55, 1-23.

1155 Boyd, R. \& Richerson, P. J. (1985). Culture and the evolutionary process. Chicago: University of Chicago Press.

Braun, D. P. \& Plog, S. (1982). Evolution of "tribal" social networks: theory and prehistoric american evidence. American Antiquity, 47, 504-525.

1160 Brewer, M. B. (2010). Intergroup Relations. In R. F. Baumeister, \& E. J. Finkel (Eds.), Advanced Social Psychology: The State of the Science (pp. 535-571). Oxford: Oxford University Press.

Bunce, J. A. \& McElreath, R. (2017). Interethnic interaction, strategic bargaining power, and the dynamics of cultural norms. Human Nature, 28, 434-456.

Bunce, J. A. \& McElreath, R. (2018). Sustainability of minority culture when inter-ethnic interaction is profitable. Nature Human Behaviour, 2, 205-212.

Chapais, B. (2009). Primeval kinship. Harvard University Press.

1170 Cronk, L. (2004). From Mukogodo to Maasai: Ethnicity and cultural change in Kenya. Boulder, CO: Westview Press.

Demps, K. \& Winterhalder, B. (2018). "Every tradesman must also be a merchant": Behavioral ecology and household-level production for barter and trade in premodern economies. Journal of Archaeological Research, 27, 49-90.

Dovidio, J. F., Gaertner, S. L. \& Kawakami, K. (2003). Intergroup contact: The past, present, and the future. Group Processes and Intergroup Relations, 6, 5-21.

Dyson-Hudson, R. \& Smith, E. A. (1978). Human territoriality: An ecological reassessment. American Anthropologist, 80, 21-41.

Ensminger, J. (1994). The political economy of religion: An economic anthropologist's perspective. Journal of Institutional and Theoretical Economics, 150, 745-754.

Fearon, J. D. \& Laitin, D. D. (1996). Explaining interethnic cooperation. American Political Science Review, 90, 715-735.

Fitzhugh, B., Phillips, S. C. \& Gjesfjeld, E. (2011). Modeling huntergatherer information networks: an archaeological case study from the kuril islands. Information and its role in hunter-gatherer bands, (pp. 85-115).

1190 Foley, R. \& Gamble, C. (2009). The ecology of social transitions in human evolution. Philosophical transactions of the Royal Society of London. Series B, Biological sciences, 364, 3267-79.

Fontana, L. (2014). The 'indigenous native peasant' trinity. Environment and Planning D: Society and Space, 32, 518-534.

1195 Gamble, C. (1999). The Palaeolithic Societies of Europe. Cambridge, UK: Cambridge University Press.

Gigerenzer, G. \& Goldstein, D. G. (1996). Reasoning the fast and frugal way: models of bounded rationality. Psychological review, 103, 650.
Gill, L. (1993). Religious mobility and the many words of God in La Paz, Bolivia. V. Garrard-Burnett y D. Stoll, Rethinking Protes- 1200 tantism in Latin America, Temple University Press, Philadelphia, (pp. 180-198).

Glowacki, L. (2020). The emergence of locally adaptive institutions. Biosystems, 198, 104257.

Godoy, R. (2015). A natural experiment in westernization. Working 1205 Paper: Heller School for Social Policy and Management.

Gurven, M., Jaeggi, A. V., Von Rueden, C. et al. (2015). Does market integration buffer risk, erode traditional sharing practices and increase inequality? . Human Ecology, 43, 515-530.

Gurven, M., Kaplan, H. \& Supa, A. Z. (2007). Mortality experience 1210 of Tsimane Amerindians of Bolivia. American Journal of Human Biology, 19, 376-398.

Henrich, J., Heine, S. J. \& Norenzayan, A. (2010). Most people are not weird. Nature, 466, 29-29.

Hruschka, D. J., Munira, S., Jesmin, K. et al. (2018). Learning from 1215 failures of protocol in cross-cultural research. Proceedings of the National Academy of Sciences, 115, 11428-11434.

Huanca, T. L. (2008). Tsimane' oral tradition, landscape, and identity in tropical forest. South-South Exchange Programme for Research on the History of Development. La Paz, Bolivia.

Irwin, G., Shaw, B. \& Mcalister, A. (2019). The origins of the Kula Ring: Archaeological and maritime perspectives from the southern Massim and Mailu areas of Papua New Guinea. Archaeology in Oceania, 54, 1-16

Jha, S. (2013). Trade, institutions, and ethnic tolerance: Evidence from 1225 south asia. American political Science review, 107, 806-832.

Johnson, A. J., Becker, J. A., Craig, E. A. et al. (2009). Changes in friendship commitment: Comparing geographically close and longdistance young-adult friendships. Communication Quarterly, 57, 395415.

Jones, J. H., Ready, E. \& Pisor, A. C. (2021). Want climate-change adaptation? Evolutionary theory can help. American Journal of Human Biology, (p. e23539).

Kelly, R. L. (2007). The Foraging Spectrum: Diversity in Huntergatherer Lifeways. (2nd ed.). Clinton Corners, NY: Percheron Press. 1235

Klein, H. S. (2011). A concise history of Bolivia. Cambridge University Press.

Kummer, H. (1971). Primate Societies: Group Techniques of Ecological Adaptation. London: Routledge.

Lang, M., Purzycki, B. G., Apicella, C. L. et al. (2019). Moralizing 1240 gods, impartiality and religious parochialism across 15 societies. Proceedings of the Royal Society B, 286, 20190202.

Lathrap, D. W. (1973). The antiquity and importance of long-distance trade relationships in the moist tropics of pre-Columbian South America. World Archaeology, 5, 170-186.

Layton, R., O’Hara, S. \& Bilsborough, A. (2012). Antiquity and social functions of multilevel social organization among human huntergatherers. International Journal of Primatology, 33, 1215-1245.

Llojlla Roca, J. M. (2011). Historial de Tucupí.

Malinowski, B. (1922). Argonauts of the western pacific, .

Mamani, V. H., S. M. \& Huasna Bozo, J. (2010). Tsinsi Tsä'si Tsinsi Chhuyitidye. Pueblo Mosetén de Covendo. Cochabamba, Bolivia: Eibamaz, UMSS, UNICEF y PROEIB Andes.

McConvell, P. (2015). Long-distance diffusion of affinal kinship terms as evidence of late holocene change in marriage systems in aborigi- 1255 nal australia. In Strings of Connectedness: Essays in Honour of Ian Keen (p. 287). Australian National University Press.

McElreath, R., Boyd, R. \& Richerson, P. (2003). Shared norms and the evolution of ethnic markers. Current Anthropology, 44, 122-130.

Minnis, P. E. (1985). Social adaptation to food stress. University of 1260 Chicago Press.

Mintz, S. W. \& Wolf, E. R. (1950). An analysis of ritual co-parenthood (compadrazgo). Southwestern Journal of Anthropology, 6, 341-368.

Moya, C. \& Boyd, R. (2015). Different selection pressures give rise to distinct ethnic phenomena. Human Nature, 26, 1-27.

Newman, L. \& Dale, A. (2007). Homophily and agency: Creating effective sustainable development networks. Environment, Development and Sustainability, 9, 79-90.

Nichols, A. L. \& Maner, J. K. (2008). The good-subject effect: Investigating participant demand characteristics. The Journal of general 1270 psychology, 135, 151-166. 
Nordenskiöld, E. (2001). Exploraciones y aventuras en Sudamérica. La Paz, Bolivia: Apoyo para el Campesino Indígena del Oriente Boliviano (APCOB).

Pan, L. (2009). Risk pooling through transfers in rural Ethiopia. Economic Development and Cultural Change, 57, 809-835.

Pettigrew, T. F. \& Tropp, L. R. (2006). A meta-analytic test of intergroup contact theory. Journal of personality and social psychology, 90, 751-783.

Pietraszewski, D. (2021). Towards a computational theory of social groups: A finite set of cognitive primitives for representing any and all social groups in the context of conflict. Behavioral and Brain Sciences, (pp. 1-62)

Pisor, A. C., Gervais, M. M., Purzycki, B. et al. (2020). Preferences and constraints. Royal Society Open Science, 7, 192090.

Pisor, A. C. \& Gurven, M. (2016). Risk buffering and resource access shape valuation of out-group strangers. Scientific reports, 6, 1-10.

Pisor, A. C. \& Gurven, M. (2018). When to diversify, and with whom? Evolution and Human Behavior, 39, 30-39.

1290 Pisor, A. C. \& Jones, J. H. (2021). Do people manage climate risk through long-distance relationships? American Journal of Human Biology, 33, e23525.

Pisor, A. C. \& Ross, C. T. (2021). How generalizable are patterns of parochial altruism in humans?,.

Pisor, A. C. \& Surbeck, M. (2019). The evolution of intergroup tolerance in nonhuman primates and humans. Evolutionary Anthropology, 28, 210-223.

Policarpo, V. (2016). "The Real Deal": Managing Intimacy Within Friendship at a Distance. Qualitative Sociology Review, 12, 23-42.

Purzycki, B. G., Apicella, C., Atkinson, Q. D. et al. (2016). Moralistic gods, supernatural punishment and the expansion of human sociality. Nature, 530, 327.

Rao, V. R. et al. (2014). Applied conjoint analysis. Springer.

Reeve, M.-E. (1993). Regional interaction in the Western Amazon. Ethnohistory, (pp. 106-138).

Reyes-García, V., Ruiz-Mallén, I., Huanca, T. et al. (2010). Integration to the market economy, social capital, and credit. TAPS Working Paper.

Richerson, P., Baldini, R., Bell, A. V. et al. (2016). Cultural group selection plays an essential role in explaining human cooperation. Behavioral and Brain Sciences, 39

Riek, B. M., Mania, E. W. \& Gaertner, S. L. (2006). Intergroup threat and outgroup attitudes: A meta-analytic review. Personality and Social Psychology Review, 10, 336-353.

1315 Ringhofer, L. (2010). Exploring an indigenous world in the Bolivian Amazon. In Fishing, foraging and farming in the Bolivian Amazon (pp. 45-82). Springer.

Ross, R. M. \& Atkinson, Q. D. (2016). Folktale transmission in the Arctic provides evidence for high bandwidth social learning among hunter-gatherer groups. Evolution and Human Behavior, 37, 47-53. Sakel, J. (2011). Mosetén and chimane argument coding: A layered system. International Journal of American Linguistics, 77, 537557.

Sherif, M. (1966). In common predicament;: Social psychology of intergroup conflict and cooperation. Houghton Mifflin.

Siete, P. (2019). 74,9cristiano-evangélicos. Página Siete,

Singh, M. \& Glowacki, L. (2021). Human social organization during the Late Pleistocene: Beyond the nomadic-egalitarian model. EcoEvoRXiv preprint, (pp. 1-21).

1330 Smaldino, P. E. (2019). Social identity and cooperation in cultural evolution. Behavioural Processes, 161, 108-116.

Smith, D., Schlaepfer, P., Major, K. et al. (2017). Cooperation and the evolution of hunter-gatherer storytelling. Nature Communications, 8,1853 .

1335 Smith, K. M. \& Apicella, C. L. (2020). Partner choice in human evolution: The role of cooperation, foraging ability, and culture in Hadza campmate preferences. Evolution and Human Behavior, 41, 354 366.

Spielmann, K. A. (1986). Interdependence among egalitarian societies. Journal of Anthropological Archaeology, 5, 279-312.

Sterelny, K. (2011). Civilizing cooperation: Paul Seabright and the Company of Strangers. Biological Theory, 6, 120-126.

Sterelny, K. (2016). Cooperation, culture, and conflict. The British Journal for the Philosophy of Science, 67, 31-58.
Sterelny, K. (2018). Religion re-explained. Religion, Brain and Behav- 1345 ior, 8, 406-425.

Stoll, D. (1990). Is Latin America turning protestant?. University of California Press.

Tooby, J., Cosmides, L. \& Price, M. E. (2006). Cognitive adaptations for n-person exchange: the evolutionary roots of organizational be- 1350 havior. Managerial and Decision Economics, 27, 103-129.

Tucker, B. (2017). From risk and time preferences to cultural models of causality: On the challenges and possibilities of field experiments, with examples from rural Southwestern Madagascar. In J. R. Stevens (Ed.), Impulsivity: How Time and Risk Influence Decision 1355 Making (pp. 61-114). New York, NY: Springer International Publishing.

Varughese, G. \& Ostrom, E. (2001). The contested role of heterogeneity in collective action: Some evidence from community forestry in Nepal. World Development, 29, 747-765.

Whallon, R. (2006). Social networks and information: Non"utilitarian" mobility among hunter-gatherers. Journal of Anthropological Archaeology, 25, 259-270.

Wiessner, P. (1977). Hxaro: a Regional System of Reciprocity for Reducing Risk among the !Kung San. Ph.D. thesis.

Wiessner, P. (1982). Risk, reciprocity and social influences on kung san economics. In E. B. Leacock, \& R. B. Lee (Eds.), Politics and history in band societies (pp. 61-84). CUP Archive.

Wiessner, P. (1984). Reconsidering the behavioral basis for style: A case study among the Kalahari San. Journal of Anthropological 1370 Archaeology, 3, 190-234.

Wobst, H. M. (1978). The archaeo-ethnology of hunter-gatherers or the tyranny of the ethnographic record in archaeology. American Antiquity, 43, 303-309.

World Bank (2020). Climate change knowledge portal. Bolivia.

Yengoyan, A. A. (1968). Demographic and ecological influences on Aboriginal Australian marriage sections. In R. B. Lee, \& I. DeVore (Eds.), Man the Hunter (pp. 185-199). Chicago: Aldine Publishing Company.

Yount, J. W., Tsiazonera \& Tucker, B. T. (2001). Constructing Mikea 1380 identity: Past or present links to forest and foraging. Ethnohistory, 48, 257-291 


\title{
Supplementary Information: Distinguishing intergroup and long-distance relationships
}

\author{
Anne C. Pisor ${ }^{1,2}$ and Cody T. Ross ${ }^{2}$ \\ ${ }^{1}$ Department of Anthropology, Washington State University. \\ ${ }^{2}$ Max Planck Institute for Evolutionary Anthropology. Dept. of Human Behavior, Ecology and Culture.
} Germany.

\section{Contents}

1 The choice task

1.1 Data collection ............ 1

1.2 Data preparation . . . . . . . . . 1

1.3 Statistical modeling . . . . . . . . . 2

1.4 Game play and the choice task ..... 3

2 Results

2.1 The effects of card characteristics on card choice . . . . . . . . . .

2.2 The effects of economic game play on card choice ............ . 4

Data, metadata, and code for this study are available at www.gi thub.com/annethro/parochialism

\section{The choice task}

\subsection{Data collection}

Participants ( $\mathrm{n}=120 ; 40 \%$ female) were interviewed by ACP and two research assistants in April-June 2017. Participants received monetary compensation for their time. Study protocol were approved by the communities and the Mosetén tribal organization. Given mixed literacy but familiarity with signing forms, participants were read a consent form and provided their written consent via signature. All field protocols were approved by the Max Planck Institute for Evolutionary Anthropology Department of Human Behavior, Ecology, and Culture, and declared exempt from additional IRB oversight.

ACP presented participants with pairs of cards representing hypothetical individuals - each described by six categories of characteristics (Figure 1). The levels for these six categories were as follows (translated from Spanish):

- Location: this community, the other side of the river valley, La Paz.

- Pueblo indígena: Mosetén, Tsimane', Aymara, Quechua, Trinitario
- Religious affiliation: Catholic, Evangelical

- Trustworthiness: not trustworthy, trustworthy, very trustworthy

- Good person: not a good person, good person, very good person

- Wealth: does not have money, has money, has lots of money

ACP generated the complete orthogonal array of cards for these six categories and their levels using a Latin square design such that each card in the array differed by at least one level on one of the six categories. ACP randomly sampled 180 cards from this array and randomly sorted them into 90 pairs (without replacement; cf. Rao et al. (2014)) using the mix-and-match method in the $\mathrm{R}$ package support. CEs (version 0.4.1; Aizaki (2012)). These pairs were then randomly assigned to five blocks; within each block, the pair was randomly assigned an order (1-18) and one card was randomly assigned to appear on the left. To control for any effects of the order of presentation of the six categories, the order of the six categories was randomized into two versions of each block, creating 10 total versions of the task (e.g., Version 1, from the top of the card to the bottom: religious affiliation, trustworthiness, pueblo indígena, location, good person, and wealth (Figure 1); Version 2: trustworthiness, wealth, religious affiliation, good person, location, pueblo indígena). Each participant was presented with one of 10 versions of the choice task and made 18 sequential decisions between pairs of cards.

\subsection{Data preparation}

Choice task design, data preparation, and analyses were conducted using R version 4.0.2 (R Core Team 2016).

To reduce participant identifiability, we binned participant ages into 5-year bins (e.g., an age of 36 was rounded to 40; an age of 21 was rounded to 20). To aid in model estimation, we normalized net household income- that is, the participant's household's estimated income over the last month, minus their estimated 


$\begin{array}{ll}8 & 8 \\ \text { Católico } & \text { Católico } \\ \text { Confiable } & \text { Muy confiable } \\ \text { Quechua } & \text { Tsimane' } \\ \text { Este distrito } & \text { Ciudad de La Paz } \\ \text { Muy buena gente } & \text { Buena gente } \\ \text { Tiene plata } & \text { Tiene plata }\end{array}$

Fig. 1: An example of one of the 18 sequential decisions made by each participant in the paired comparison choice task. The codes at the bottom right indicate that this pair was the fourth presented to participants who completed the first version of the task; the card marked "L" always appeared on the left and "R" always on the right.

expenditures-years of schooling, and age such that a value of 0 represents the sample mean and a value of 1 represents one standard deviation. We also normalized the average amount given to out-group candidate recipients in the 2014-15 economic game for the models described in section 1.4

Of the 120 total participants, 13 reported having no religious affiliation and one was not asked about their years of schooling. Given our interest in whether participants are choosing candidate friends based on religious affiliation and our inclusion of years of schooling as a control, we imputed these data using predictive mean matching, implemented with the mice package (version 3.10.0; Van Buuren and Groothuis-Oudshoorn (2011)).

\subsection{Statistical modeling}

We used a Bernoulli mixed-effect model with logistic link to investigate which card characteristics predicted a participant's choice of the right-hand card. Since the choice between two cards in a pair was binary, our decision to model participants' decisions using the right-hand card was arbitrary; we could just as easily have picked the left-hand card. We parameterized models such that estimates reflect contrasts to lower levels-that is, "ingroups" (i.e., same community, same pueblo indígena, same religious affiliation) and the absence of a quality (i.e., a bad person, someone who is not wealthy, someone who is not trustworthy) - and can be compared to no difference between cards. For example, consider the combinations for Location: Same Valley and Location: City in Table 1.

In Row $\mathrm{A}$, the indices indicate that the candidate friend on the left-hand side was from the same river valley, as -1 indicates the presence of the level on the left; the candidate friend on the right-hand side was from the city, as indicated by the 1 . By extrapolation, then, neither candidate friend was from the same community. In Row B, the candidate friend on the right-hand side was from the same valley. Because the value for Location: City is 0 -indicating that either both candidate friends are from the city, or neither is - but we know that the right-hand candidate friend is from the same valley, that means that neither is from the city and therefore the lefthand candidate friend is from the same community. In Row $\mathrm{C}$, the coding scheme does not reveal where the candidate friends are from, but rather that there is no difference between the two: they both are in the same location, regardless of which location that is. This coding scheme means that parameter estimates for Location tell us whether (i) a participant is more likely to pick the right-hand candidate if they live further away than the candidate on the left-hand side, and (ii) whether there's something specific about living in the same valley or living in the same city that participants use to make their decision. An alternative coding scheme that tells us just (i), not (ii), is described and implemented in our code for comparison (available at www . gi thub.com/annethro/ parochialism).

Data are coded such that pueblo indígena and religious affiliation are specific to the participant, based on how they self-identified in census data. For example, imagine a participant who self-identified as Evangelical and Quechua. If she is shown the two cards in Figure 1, this is coded as 1 for pueblo indígena-her own pueblo indígena appears on the left, whereas a different pueblo indígena appears on the right - and coded as 0 for religious affiliation-the same religious affiliation appears on both cards.

Models were implemented with the brms package (Bürkner 2017), which passes Bayesian models to Stan (Stan Development Team 2019). We used weakly informative priors. For fixed effects, given parameters in logistic models are on a scale of 0-1 before they pass through the link function, we used a normal prior with a mean of 0 and standard deviation of 1 . For random effects, given the traceplots of initial model runs, we used an exponential distribution with a rate parameter of 1 to make exploration of the parameter space more efficient. For a discussion of the choice of priors, see (McElreath 2016).

We fit models both with controls and without. We anticipated that participant age, sex, years of schooling, and 
Table 1: The potential combinations of values for Location: Same Valley and Location:City on two cards.

$\begin{array}{lcr}\text { Row } & \text { Loc.SameValley_Diff } & \text { Loc.City_Diff } \\ \text { A } & -1 & 1 \\ \text { B } & 1 & 0 \\ \text { C } & 0 & 0\end{array}$

household net income over the previous month might affect preferences for a candidate friend who lived at a distance, was part of a different pueblo indígena, or was of a different religious affiliation. For example, because mobility is higher among males than females and, thanks to access to roads, has been higher for a larger proportion of younger individuals' adult lives, sex and age affect exposure to individuals at a distance or from other pueblo indígenas and could impact preferences accordingly (Pisor and Jones 2020). Because the outcome of our models was choosing the right-hand card, treating controls as additive did not make sense: this would control for preferences for choosing right, not preferences for choosing someone who lived at a distance, for example. Instead, fit a separate model including each control, interacting the control with the predictors of interest: candidate friend location, pueblo indígena, and religious affiliation. As the inclusion of each control did not qualitatively alter the results of the model fit with no controls, we report the model without controls in the main text.

\subsection{Game play and the choice task}

We analyzed whether average giving to candidate recipients from a different pueblo indígena in 2014-15 was associated with preferring candidate friends from a different pueblo indígena in 2017; we did the same for candidate recipients and friends with a different religious affiliation. We also explored whether out-group giving, regardless of whether the out-group was religious or a pueblo indígena, predicted preferring candidate friends living at a distance.

A subset of 80 participants ( $50 \%$ female) completed both the choice task and the 2014-15 economic game; the latter is described in (Pisor and Gurven 2016, 2018). Participants completed a sorting task in which they identified which pueblos indígenas and religious affiliations they identified with the most (1) and the least (5). From this, we classified a participant's in-groups as those in the first or second positions, out-groups as those in the fourth and fifth positions, and "intermediate" groups as those in the third position. Of the 80 participants who completed both the choice task and the game, 63 identified out-groups and were thus presented with candidate recipients who were identified as part of a religious or pueblo indígena out-group. Because the other 17 did not identify out-groups, they were either presented with one in-group and one intermediate group or two in-groups; given our interest in out-group giving, we excluded them from analysis accordingly.
To check for a relationship between how a participant played in the economic game and their choices in the choice task, we interacted the average amount they gave to out-group members in the economic game with (i) their choice of someone from a different pueblo indígena or religion and (ii) their choice of someone from a different location on the choice task. We implemented this as follows:

1. We interacted the pueblo indígena of candidate friends from the choice task with (i) whether the participant was told the pueblo indígena or religion of candidate recipients in the 2014-15 economic game and (ii) the amount the participant gave to each outgroup member on average-a three-way interaction. We did the same for the religion of candidate friends from the choice task.

2. We interacted the location of candidate friends from the choice task with the amount the participant gave to each out-group member on average- a two-way interaction.

Models were fit both with and without controls. As before, we fit a separate model with each control included, interacting controls with the predictors of interest, described in A and B immediately above, to create four-way and three-way interactions. We fit one model with each of the controls described in Section 1.3. We also included three additional controls. The first was planned: whether the participant chose to give money anonymously in the 2014-15 economic games. (Some participants strongly wished to do so, so ACP allowed them this option; see Pisor and Gurven (2016, 2018) for details.) The second and third were included as exploratory analyses. Household net income over the previous month was entirely uncorrelated $(\mathrm{r}=-0.01)$ between 2014-15 and 2017. This may be because ACP conducted the interviews in spring and summer in 2014-15 and in fall in 2017, and cash crop incomes vary substantially by season; however, it may also reflect changes in household circumstances in the intervening two years that could affect preferences. Accordingly, we explored the effects of controlling for (i) household net income in 2014-15 and (ii) the difference in household income between 2017 and 2014-15 on model estimates.

Model specification was otherwise identical to that described above (in Section 1.3). Using predictive mean matching, as described in Section 1.3, we imputed data for three people without a religious affiliation and one person missing data on their schooling. As the inclusion of each control did not qualitatively alter the results of the model with no controls, we report the model without controls in the main text. 


\section{Results}

Models with and without controls returned qualitatively similar results; we thus report models including controls here. Again, models estimate the probability of picking the right-hand card based on the qualities that appear on the left or on the right. For simplicity, we focus on estimates for picking the right-hand card based on the characteristics of the right-hand card in the text, as the two estimates are essentially mirror images of one another; for completeness, however, we plot both in Figure 2. All estimates are non-standardized means and $90 \%$ credible intervals.

\subsection{The effects of card characteristics on card choice}

Participants preferred candidate friends who were not from La Paz, the capital city of Bolivia; we can infer this because when the candidate friend on the righthand side was from La Paz but the candidate friend on the left-hand side was not, participants were less likely to pick the right-hand card. They also preferred candidate friends not from the same river valley - at least when a candidate friend from the same river valley appeared on the right. Taken together, we can infer that they preferred same-community candidate friends over friends from elsewhere. Likewise, participants preferred candidate friends from their own pueblo indígena and their own religious affiliation over those from other pueblos indígenas and other religious affiliations. Note that these latter effects are more pronounced than the effect of location, as participants consistently avoided candidate friends from other pueblos indígenas or other religious affiliations regardless of whether they appeared on the left or right.

Consistent with preferences elicited in the 2014-15 economic game, participants strongly preferred candidate friends who were "good people" or "very good people" - this was the largest effect observed (Pisor and Gurven 2018). Participants also preferred participants who were "trustworthy" or "very trustworthy," although like that of location, this effect depended on whether trustworthy candidate friend appeared on the left or right. Participants avoided picking candidate friends described as having "a lot of money."

Older participants were more likely to prefer a candidate friend of the same religious affiliation when they appeared on the left and participants with higher net incomes were more likely to prefer someone not from the same river valley when they appeared on the left. Other controls did not predict choice of candidate friend.

\subsection{The effects of economic game play on card choice}

The posterior means and $90 \%$ credible intervals for the predictors of interest are reported in Figure 3. The average amount given by a participant to candidate out-group recipients in the $2014-15$ economic game was not re- lated to whether participants chose cards in 2017 based on their out-group membership - regardless of whether the candidate friends on the cards or the candidate recipients in the game were from a different pueblo indígena or had a different religious affiliation. Likewise, the average amount given by a participant to candidate outgroup recipients in 2014-15 was not related to whether they chose cards in 2017 based on their location.

With respect to the effects of card characteristics reported in Section 2.1, the $90 \%$ credible interval included an OR of 1 (that is, the magnitude of effect was reduced such that we cannot rule out no effect) for a candidate friend living in $\mathrm{La} \mathrm{Paz}$, if on the right-hand side; from a different pueblo indígena, if on the left-hand side; and having a lot of money, if on the left-hand side. Note that the different in qualitative magnitude of the estimates between the model including card characteristics (Section 2.1) and the model including both card characteristics and economic game play (this section) is unsurprising given the sample size also differs $(n=120$ in Section 2.1, $\mathrm{n}=63$ in this section).

Keeping in mind this difference in sample size, the inclusion of controls reduced the magnitude of the following effects of card characteristics:

- Age. The older the participant, the more they preferred candidate friends not from the same valley on the right and not from La Paz if on the left; very trustworthy if on the left; and not "very wealthy" if on the right

- Sex. Male participants preferred candidate friends not from the same valley on the right and not from La Paz if on the left; and not "very wealthy" if on the right

- Years of schooling. Participants with more years of schooling preferred candidate friends not from the same valley on the right and not from $\mathrm{La} \mathrm{Paz}$ if on the left; from the same pueblo indígena when on the right; and not "very wealthy" if on the right

- Net income over the last month in 2017. Participants with higher net incomes in 2017 preferred candidate friends not from the same valley on the right and not from La Paz if on the left; from the same pueblo indígena when on the right; and not "very wealthy" if on the right

- Net income over the last month in 2014-15. Participants with higher net incomes in 2014-15 preferred candidate friends not from the same valley on the right and not from La Paz if on the left; and not "very wealthy" if on the right

- Difference in net income between 2017 and 201415. Participants with a larger discrepancy in their net income between 2017 and 2014-15 preferred candidate friends not from the same valley on the right and not from La Paz if on the left; from the same pueblo indígena when on the right; and not "very wealthy" if on the right

- Non-anonymous game play. Participants who played the game non-anonymously (that is, sharing 
their name and group affiliation with the recipient) preferred candidate friends not from the same valley on the right and not from La Paz if on the left; from the same pueblo indígena when on the left or the right; and not "very wealthy" if on the right

The four-way interactions between controls and the predictors of interest (described in 1 and 2 in Section 1.4) are complicated to interpret, so we refrain from doing so here and refer interested readers to the model code (available at www . gi thub. com/annethro/parochialism).

\section{References}

Hideo Aizaki. Basic functions for supporting an implementation of choice experiments in R. Journal Of Statistical Software, 50(2):124, 2012. URL http: //www. jstatsoft. org/v50/c02/.

Paul Christian Bürkner. brms: An R package for Bayesian multilevel models using Stan. Journal of Statistical Software, 80(1), 2017. ISSN 15487660.

Richard McElreath. Statistical rethinking. CRC press, 2016.

Anne C Pisor and Michael Gurven. Risk buffering and resource access shape valuation of out-group strangers. Scientific reports, 6(1):1-10, 2016.

Anne C Pisor and Michael Gurven. When to diversify, and with whom? Evolution and Human Behavior, 39(1):30-39, 2018.

Anne C. Pisor and James Holland Jones. Do people manage climate risk through long-distance relationships? American Journal of $\mathrm{Hu}$ man Biology, (e23525):e23525, 2020. . URL https://doi .org/ 10. 1002 /ajhb. 23525 .

R Core Team. R: A Language and Environment for Statistical Computing. R Foundation for Statistical Computing, Vienna, Austria, 2016. URL https: //www.R-project.org/.

Vithala R Rao et al. Applied conjoint analysis. Springer, 2014.

Stan Development Team. RStan, 2019. URL http: //mc-stan .org/. Version 2.19.2.

Stef Van Buuren and Karin Groothuis-Oudshoorn. Multivariate imputation by chained equations. Journal Of Statistical Software, 45(3): 1-67, 2011. ISSN 15487660. . URL http://igitur-archive. library.uu.nl/fss/2010-0608-200146/UUindex . html. 
Alter lives in a nearby community -

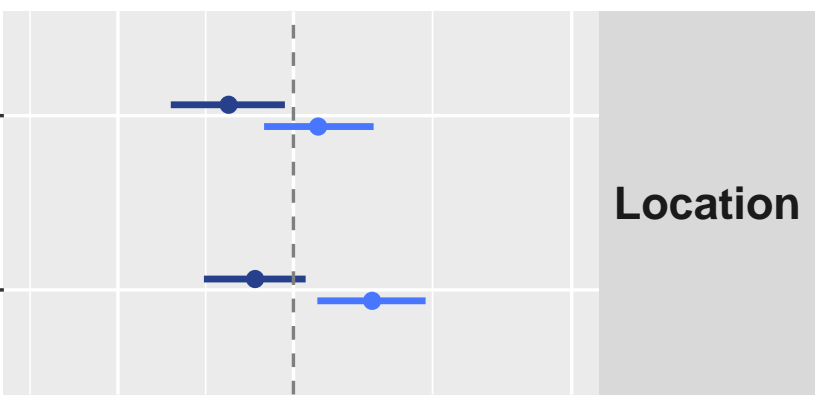

Alter lives far away in La Paz -

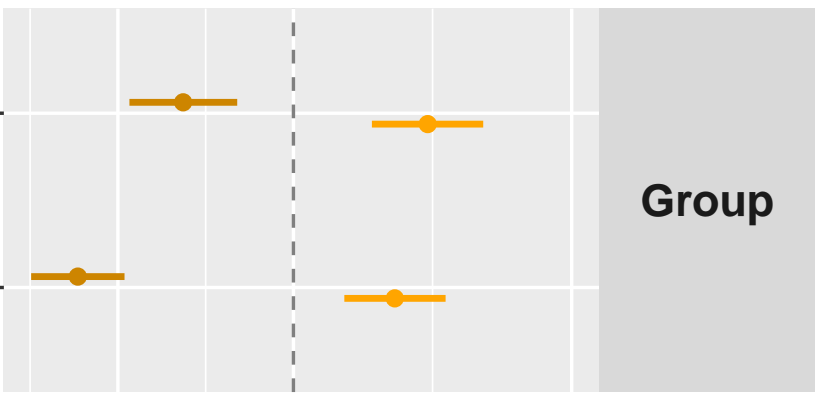

Alter is from other pueblo indígena -

Alter has other religious affiliation -

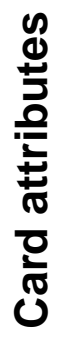

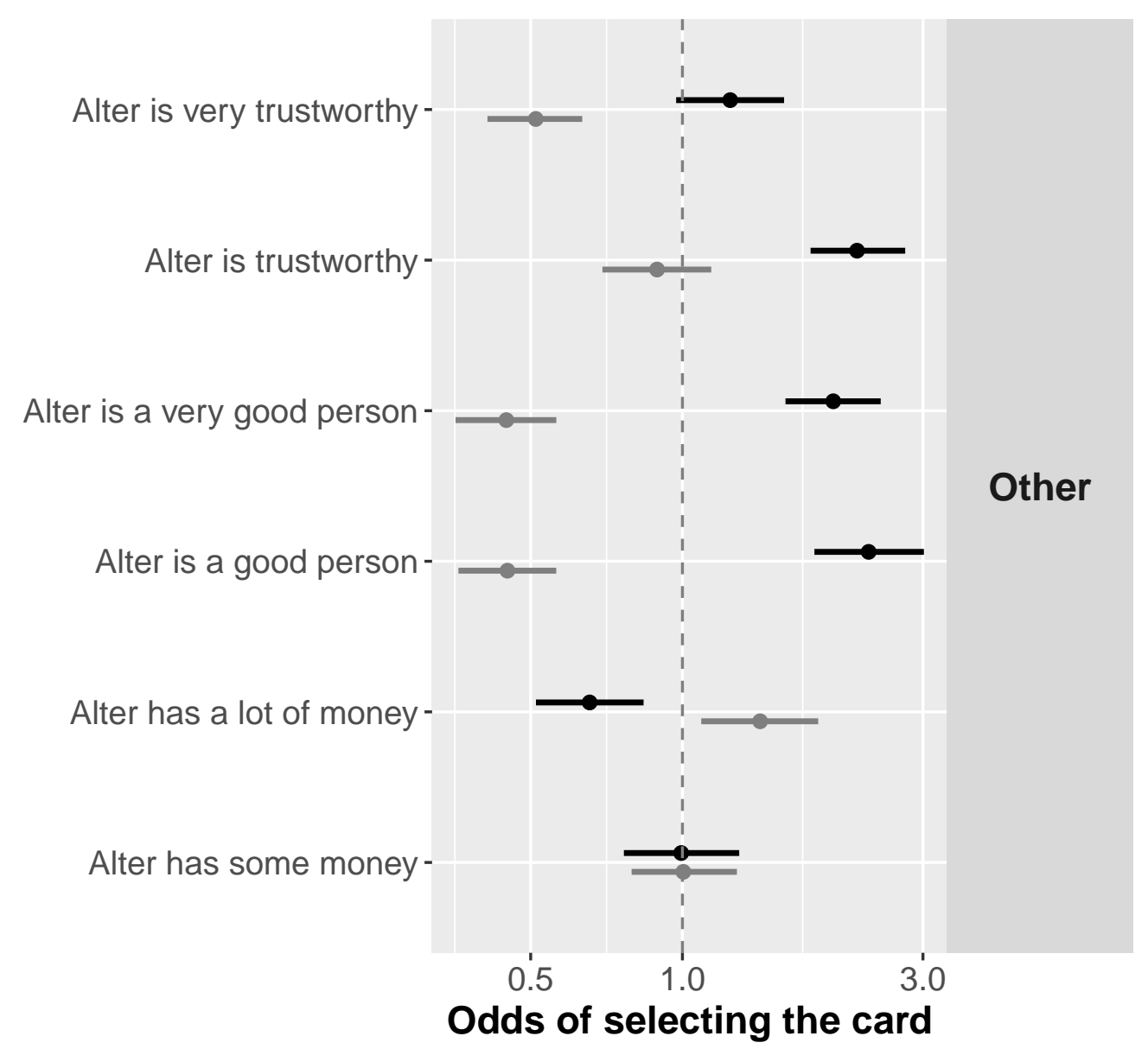

Fig. 2: Each participant was presented with a pair of hypothetical individuals and was asked which they preferred as a new friend. Each participant evaluated 18 pairs of individuals. Here, we present non-standardized estimates (means and 90\% credible regions) from a logistic regression; these estimates reflect the odds of selecting one individual if it were to differ by only a single attribute from the other individual. Different from the main text, we provide estimates for both picking the left-hand card (light colors) and the right-hand card (dark colors). The base case is a candidate friend who lives in the same community, is from the same pueblo indígena and has the same religious affiliation, and who is not good, not trustworthy, and has no money. 


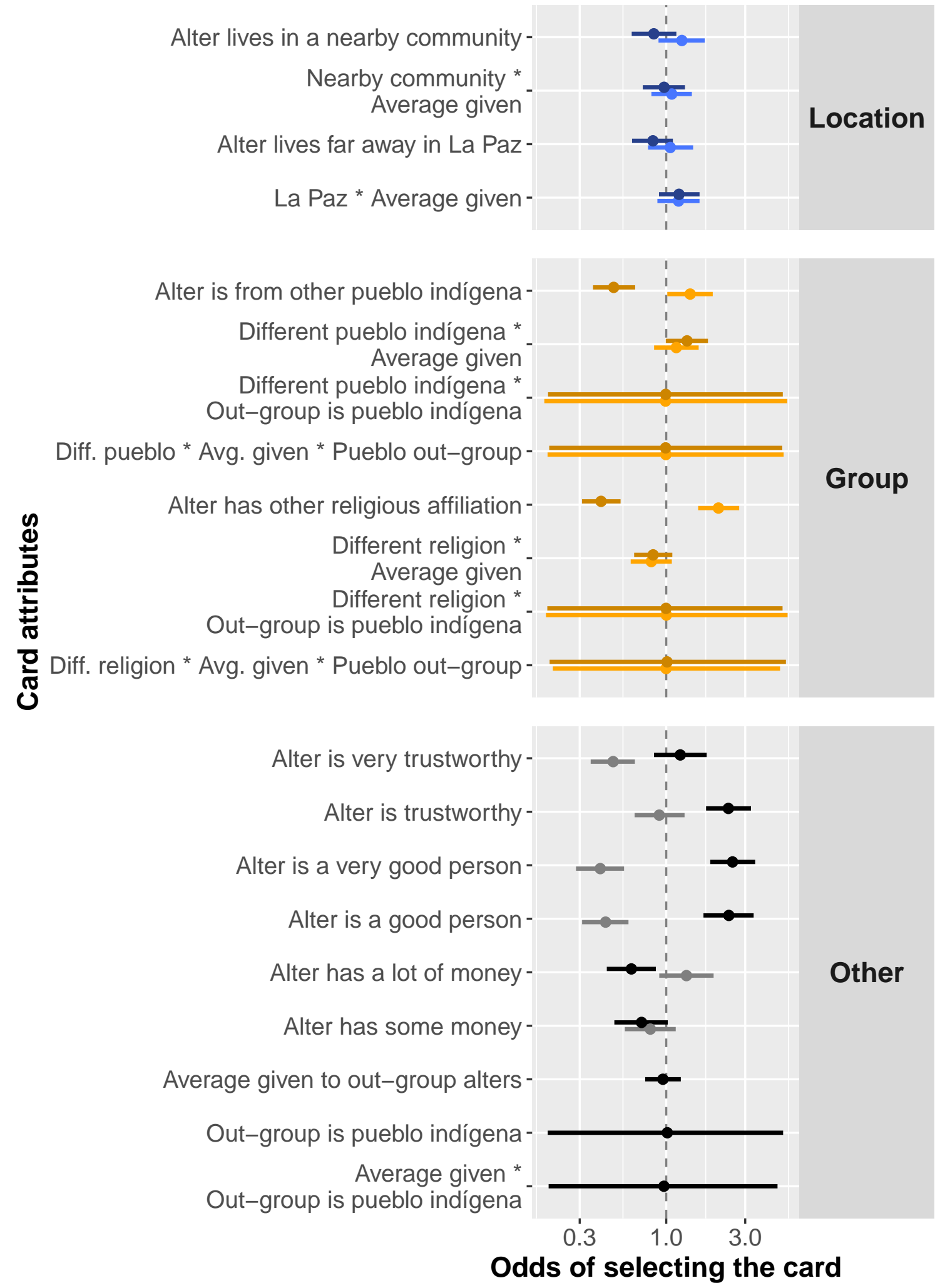

Fig. 3: A model including interactions between game play in 2014-15-average amount given to out-group members-and predictors of interest in the card choice task, including where the candidate friend lived, their religious affiliation and pueblo indígena, whether they were presented with a religious out-group or pueblo indígena out-group, and a three-way interaction between the latter two- - the participant's group membership and which out-group type they were shown. Estimates are non-standardized (means and $90 \%$ credible regions) from a logistic regression. We include estimates for both picking the left-hand card (light colors) and the right-hand card (dark colors). 